\title{
Identification of TRPV4 as a novel target in invasiveness of colorectal cancer
}

\author{
Peng Zhang ${ }^{1 *}$, Jian Xu' ${ }^{1}$, Hua Zhang ${ }^{1}$ and Xiao-Yu Liu ${ }^{2,3^{*}}$
}

\begin{abstract}
Background: Emerging evidence has indicated the critical role of TRPV4 in diverse human cancers. However, the underlying molecular mechanism of TRPV4 in colon cancer invasiveness is still unknown.

Methods: Immunohistochemistry staining was used to analyze the expression of TRPV4 and ZEB1 in clinical tissues; Wound healing and transwell assays were applied to determine the cell invasiveness; Western blot was used to explore the relation between TRPV4 and ZEB1.

Results: Colon cancer cells were transfected with siRNA against TRPV4 or HC067047 (a selective TRPV4 antagonist), TRPV4 full-length plasmid or siRNA against ZEB1, or both, in order to measure cell migration and invasion. And we found that TRPV4 silencing or inhibition exhibited an inhibitory role in colon cancer cell migration and invasion, coupled with compromised EMT process, and suppressed AKT activity. TRPV4 stimulated expression of ZEB1 and consequently contributed to EMT process and invasiveness. It was also revealed that overexpression of TRPV4 and ZEB1 in clinical patients with local metastasis, and positive correlation between TRPV4 and ZEB1.
\end{abstract}

Conclusions: Our results uncovered the role of TRPV4 in tumor metastasis and highlighted the potential mechanism of TRPV4-ZEB1 axis in indicating EMT.

Keywords: Colon cancer, TRPV4, Invasiveness, ZEB1

\section{Background}

Colorectal cancer (CRC) is the third most common human malignancy and the fourth crucial cause of cancerrelated death in worldwide [1-6]. CRC metastasis is the main cause of mortality in patients [7-9]. However, the underlying pathogenic mechanisms in CRC metastasis are still not entirely clear. Therefore, there is an urgent need to develop novel therapeutic strategies based on the molecular mechanisms of metastatic spread of CRC.

Transient receptor potential vanilloid type 4 (TRPV4) is a $\mathrm{Ca}^{2+}$-permeable nonselective cation channel that senses heat, mechanical forces and arachidonic acid [10]. TRPV4 is not only a key player in cardiovascular system

\footnotetext{
* Correspondence: zhangpeng2600@163.com; liuxy9@sustech.edu.cn 'Longgang E.N.T. Hospital \& Shenzhen Key Laboratory of E.N.T., Institute of E.N.T, No. 3004 Longgang Avenue, Shenzhen, Guangdong, China ${ }^{2}$ School of Medicine, Jiangnan University, Wuxi, Jiangsu, China Full list of author information is available at the end of the article
}

but also in cancer [11, 12]. Aberrant expression of TRPV4 is involved in diverse human cancers including colon cancer [13]. Our recent study has demonstrated that TRPV4 is associated with colon cancer development [13]. Our results illustrated that TRPV4 promotes colon cancer progression via inhibition of PTEN signaling [13]. However, TRPV4 has not been previously shown to be involved in colon cancer invasiveness, and the underlying mechanism has not been reported.

The epithelial-mesenchymal transition (EMT) can promote cancer cell losing cell polarity and cell-cell adhesion, resulting cell detachment, migration, and invasion [14]. During EMT process, the expression of E-cadherin, as an epithelial marker, is down-regulated, while the mesenchymal markers including Vimentin and $\mathrm{N}$ cadherin are increased [15]. It is well known that ZEB transcription factor families play important role in regulating EMT [16].

(C) The Author(s). 2021 Open Access This article is licensed under a Creative Commons Attribution 4.0 International License, which permits use, sharing, adaptation, distribution and reproduction in any medium or format, as long as you give appropriate credit to the original author(s) and the source, provide a link to the Creative Commons licence, and indicate if changes were made. The images or other third party material in this article are included in the article's Creative Commons licence, unless indicated otherwise in a credit line to the material. If material is not included in the article's Creative Commons licence and your intended use is not permitted by statutory regulation or exceeds the permitted use, you will need to obtain permission directly from the copyright holder. To view a copy of this licence, visit http://creativecommons.org/licenses/by/4.0/ The Creative Commons Public Domain Dedication waiver (http://creativecommons.org/publicdomain/zero/1.0/) applies to the data made available in this article, unless otherwise stated in a credit line to the data. 
In this study we explored the role of TRPV4 in CRC invasiveness in vitro and in vivo. Our findings indicated that TRPV4 exerts these functions through activating the AKT signaling pathway, regulating the expression of ZEB1 in CRC cells, and then modulating EMT. Thus, our study indicates that TRPV4 can functionally regulate EMT, suggesting a novel link between TRPV4 and colon cancer aggressiveness.

\section{Methods}

\section{Ethics statement and patients}

The Review Board of the Affiliated Hospital of Jiangnan University approved the clinical samples for research purposes (NO.LS2018020). This study was confirmed to the principles contained in the World Medical Association Declaration of Helsinki. Informed consent was requested as anonymous specimens and was given by all human participants in this study. The human colorectal cancer samples $(n=106$, without chemical treatments, paraffin embedding tissues) were randomly collected from Affiliated Hospital of Jiangnan University. Patients were recruited between 2010 and 2012 .

\section{Cell culture}

The human colon cancer cell lines SW620 was purchased from the American Type Culture Collection (ATCC, VA, USA). HCT-116 and HT-29 were purchased from the Chinese Academy of Sciences cell bank (CBCCCAS, Shanghai, China). Cell lines were maintained in McCoy's 5A or Leibovitz's L-15 medium (Thermo Fisher Scientific, MA, USA) supplemented with $10 \%$ fetal bovine serum (Thermo Fisher Scientific, MA, USA), $100 \mathrm{U} / \mathrm{mL}$ penicillin, and $100 \mu \mathrm{g} / \mathrm{mL}$ streptomycin (Thermo Fisher Scientific, MA, USA). Cells were cultured at $37^{\circ} \mathrm{C}$ with $5 \% \mathrm{CO}_{2}$ in a humidified incubator.

\section{RT-qPCR analysis}

Total RNA was isolated by Trizol (Invitrogen, CA, USA). Reverse transcription polymerase chain reaction (RT-PCR) was performed with the PrimeScript ${ }^{\mathrm{tm}}$ RT reagent kit (Takara, China) following the manufacturer's instructions. qPCR was performed using QuantiNova SYBR Green PCR Master Mix (QIAGEN, Hilden, Germany) in the LightCycler 480 Real Time PCR system (Roche, Basel, Sweden). Primer sequences are listed in the supplemental Table S1.

\section{siRNA transfection}

Cells in 12-well plate were transiently transfected with $25 \mathrm{nM}$ siRNA using DharmaFECT 1 Transfection Reagent (GE Dharmacon, CO, USA) according to the manufacturer's instructions. Briefly, adding $5 \mu \mathrm{L}$ of $5 \mu \mathrm{M}$ siRNA to $95 \mu \mathrm{L}$ of serum free medium in tube 1. Adding $5 \mu \mathrm{L}$ of DharmaFECT 1 Transfection Reagent to $95 \mu \mathrm{L}$ of serum free medium in tube 2 . Gently mix and incubate for $5 \mathrm{~min}$. Then add the contents of tube1 to tube 2 , and add $800 \mu \mathrm{L}$ of antibiotic-free complete medium for a total volume of $1000 \mu \mathrm{L}$ transfection medium. TRPV4 silencing was performed using siRNAs targeting the following sequences: siRNA\#1: 5'-AUCUUGGUAA CAAACUUGG-3', and siRNA\#2: ON-TARGET plus SMART pool against human TRPV4 siRNA (GE Dharmacon, CO, USA). ZEB1 silencing was performed using siRNA targeting the following sequences: 5 '-CAGUGU UCCAUGCUUAAGA-3'. AKT silencing was performed using siRNA targeting the following sequences: 5'GCACCUUC AUUGGCUACAATT-3'.

\section{Plasmid transfection}

The plasmid carrying human TRPV4 (GenBank NM 021625.4) was obtained from GeneCopoeia, Inc. Cells were transfected with the TRPV4 plasmid (TRPV4) or Vector using Lipofectamine ${ }^{\text {ma }} 2000$ reagent (Invitrogen, Carlsbad, CO, USA) according to the manufacturer's instructions.

\section{Western blot analysis}

Western blots were performed as previously described [17]. Primary antibodies against ACTB (Santa, TX, USA), TRPV4 (alomone labs, Israel), ZEB1, E-cadherin, $\mathrm{N}$-cadherin and Vimentin (Cell Signaling Technology, MA, USA) were incubated at $4{ }^{\circ} \mathrm{C}$ overnight with constant shaking. HRP labeled secondary antibodies (Cell Signaling Technology, MA, USA) were incubated at room temperature for $1 \mathrm{~h}$.

\section{Wound healing assay}

The wound healing assay was used a monolayer denudation assay as described previously [18]. Briefly, cells cultured in 12-well plates as confluent monolayers were mechanically scratched using a $200 \mu \mathrm{L}$ pipette tip to create the wound. Cells were washed with PBS to remove the detached cells and then cultured to allow migration. Photographs were taken and the percent of wound closure was calculated.

\section{Migration and invasion assays}

Cell migration assay was determined using the transwell chamber (Corning) as described previously [18]. Briefly, cells were harvested, washed, resuspended and then seeded into the upper chamber in serum-free medium. The medium containing 10\% FBS was placed in the lower chamber and the cells were further incubated for $24 \mathrm{~h}$, cells in the upper chamber were removed with a cotton swab, and the rest of the membrane had invaded the cells. Cells migrated through the membrane were fixed with $4 \%$ paraformaldehyde and stained with crystal violet. Cell invasion was determined with Matrigel 
matrix (BD Biosciences) coated on the upper surface of the transwell chamber. Cells were seeded, fixed and stained as described in migration assay.

\section{Immunohistochemistry staining}

Immunohistochemistry staining was performed as previously described [19]. Primary antibodies against TRPV4 (ACC-034, alomone labs, Israel) and ZEB1(\#70512, Cell Signaling Technology, MA, USA) were used. All staining was assessed by pathologists blinded to the origin of the samples and patient outcomes. The widely-accepted German semi-quantitative scoring system was used to assess the staining intensity and proportion of stained cells. Each specimen was assigned a score according to the intensity of staining ( 0 , none; 1 , weak; 2 , moderate; 3 , strong) and the proportion of stained cells $(0,0 \% ; 1,1-24 \% ; 2,25-$ $49 \%$; $3,50-74 \% ; 4,75-100 \%)$. The final score for immunoreactivity was determined by multiplying the intensity by the proportion, ranging from 0 to 12 .

\section{Statistical analyses}

Statistical analysis was performed using two-tailed Student's t-test or one-way ANOVA. All analyses were carried out with the GraphPad Prism software version 5.0 (GraphPad Software, CA, USA). Data were expressed as mean \pm standard error of the mean (SEM) of at least three independent experiments. The difference was considered significant if $p$ value $<0.05$.

\section{Results}

Inhibition of TRPV4 expression or activity suppresses colon cancer cell migration and invasion

To determine the effect of inhibition of TRPV4 on invasiveness in CRC cells, we performed migration assays using transwell in HCT-116 and SW620 cells. TRPV4 siRNAs were used to knockdown the expression of TRPV4 [13]. Pharmacological inhibiting TRPV4 was performed using HC-067047, a selective TRPV4 antagonist [13]. Our data showed that HCT-116 and SW620 cells exhibited suppressed migration when transfected with TRPV4 siRNAs when compared to cells that were transfected with control siRNA (Fig. 1A and B). We further observed that inhibition of TRPV4 activity by HC067047 decreased cell migration of HCT-116 and SW620 cells (Fig. 1B). In line with these results, HCT-116 cells exhibited a reduced migration capability at $24 \mathrm{~h}$ and $48 \mathrm{~h}$ when treated with TRPV4 siRNAs (Fig. 1C and D). Furthermore, we assessed HCT-116 and SW620 cell invasion using transwells that were coated with Matrigel. The results of the invasion assay indicated that HCT-116 and SW620 cells treated with TRPV4 siRNAs or HC-067047 had a decreased invasion ability when compared with control cells (Fig. 1E and F). Moreover, TRPV4 silencing or inhibition also suppressed migration and invasion in HT-29 cells (Supplementary Fig. S1). Taken together, these findings strongly indicated that TRPV4 inhibition suppressed cell invasiveness in CRC cells.

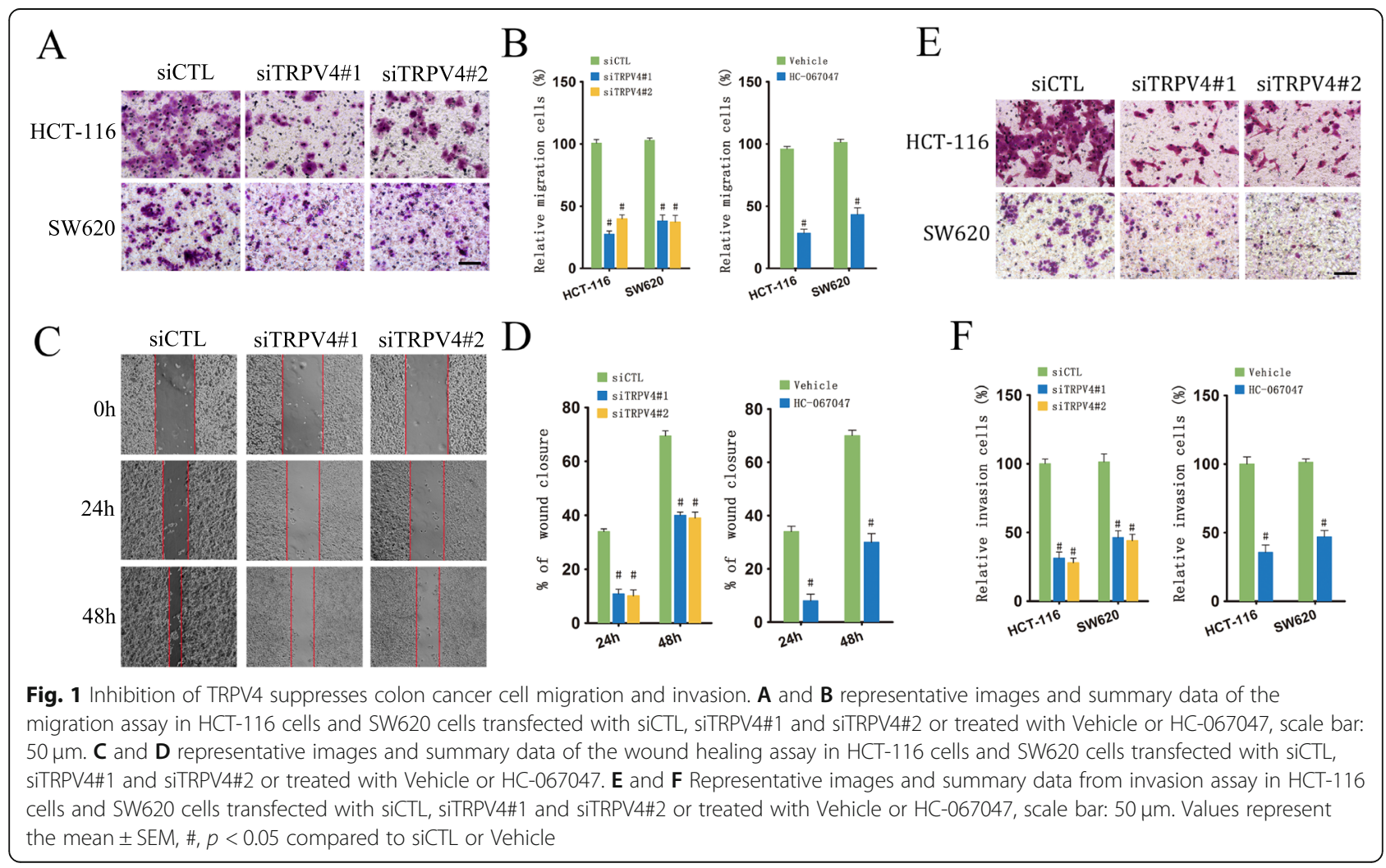




\section{TRPV4 overexpression promotes colon cancer cell} migration and invasion

To further explore the role of TRPV4 in cell migration and invasion in CRC cells, HT-29 cells were transfected with full-length human TRPV4. Our data showed that both TRPV4 mRNA and protein levels were increased in TRPV4-overexpression cells (Fig. 2A, B and I). HT-29 cells exhibited an increased migration capability when transfected with full-length human TRPV4 when compared to cells which were transfected the vector plasmid (Fig. 2C). Consistent with these results, in the invasion assay, HT-29 cells that overexpressed TRPV4 showed markedly enhanced invasion capacity when compared to control cells (Fig. 2D). Moreover, TRPV4 overexpression also increased migration and invasion in HCT-116 and SW620 cells (Supplementary Fig. S2). Taken together, these findings suggested that TRPV4 might promote cell invasiveness in CRC cells.

TRPV4 inhibition attenuates the EMT process in CRC cells In previous studies, it was shown that EMT played an important role in normal development and cancer metastasis, induced a reversible change in cell phenotype, and resulted in mesenchymal features [20]. Consequently, we explored whether TRPV4 was involved in regulating EMT. After pharmacologic inhibition with

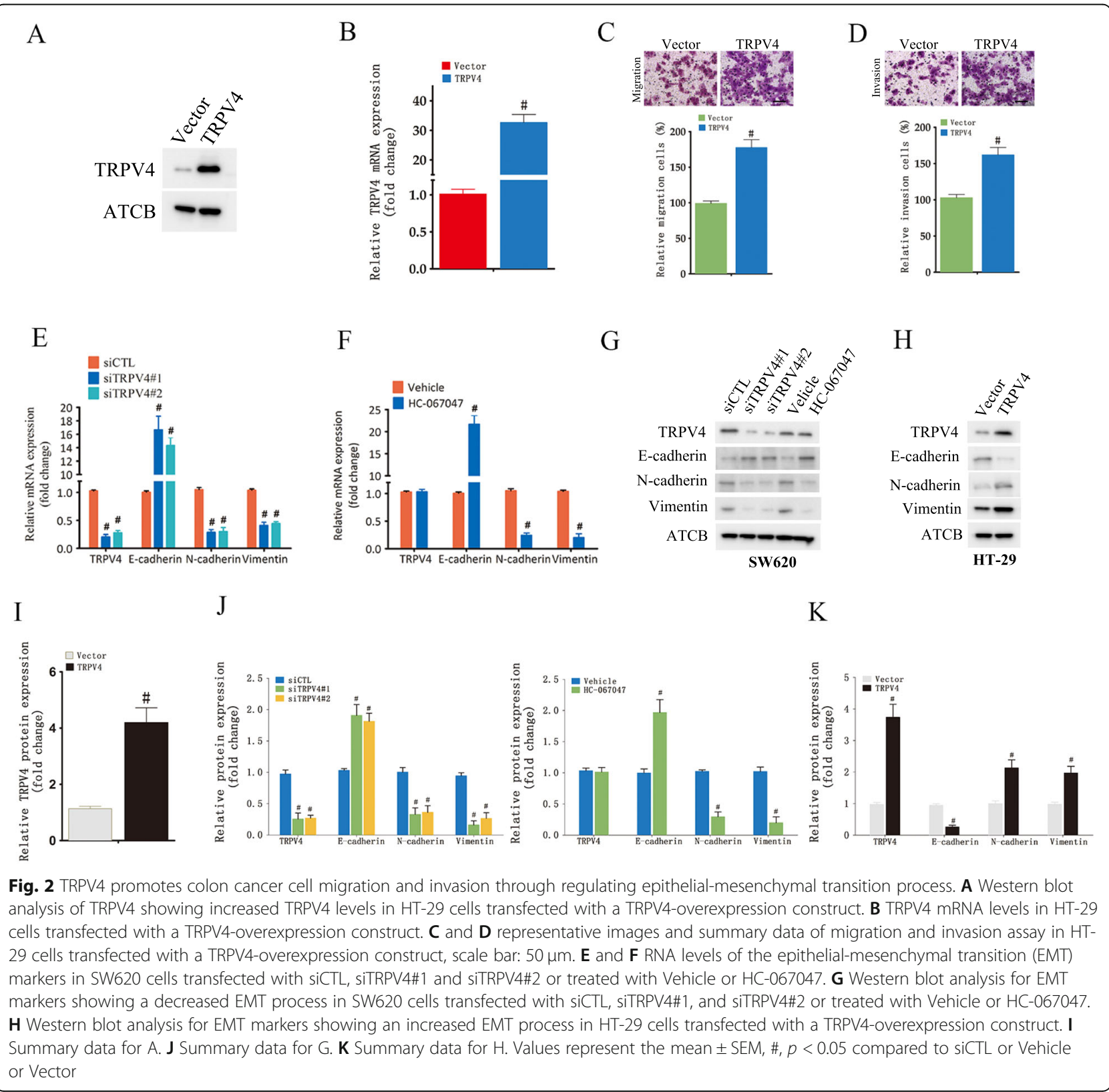


HC-067047 or gene-silencing with TRPV4 siRNA, SW620 and HT-29 cells showed increased mRNA expression of the epithelial marker E-cadherin and reduced expression of mesenchymal markers $\mathrm{N}$-cadherin and Vimentin (Fig. 2E and F and Supplementary Fig. S3). Western blot analysis further confirmed that E-cadherin was upregulated at the protein level and that protein levels of $\mathrm{N}$-cadherin and Vimentin were downregulated (Fig. 2G and J). Not surprisingly, our data showed that in TRPV4-overexpressing HT-29, HCT-116 and SW620 cells, levels of E-cadherin were decreased and levels of $\mathrm{N}$-cadherin and Vimentin were increased (Fig. $2 \mathrm{H}$ and $\mathrm{K}$ and Supplementary Fig. S4). Together, these findings strongly suggested that TRPV4 indicated EMT to promote CRC metastasis.

\section{TRPV4 increased ZEB1 expression to indicate EMT}

In previous studies, it was demonstrated that transcriptional factors, including Twist, ZEB, and Snail families induced EMT, and that ZEB1 played a critical role in the regulation of EMT in CRC [21, 22]. Therefore, in this study, we evaluated whether TRPV4 regulated the expression of ZEB1 in CRC cells. TRPV4 knockdown significantly suppressed the expression of ZEB1 in HCT116 and SW620 cells (Fig. 3A). Increasing evidence has suggested that AKT signaling could activate ZEB1 transcription [18]. Indeed, we confirmed that p-AKT expression was reduced after TRPV4 silencing or inhibition (Fig. 3A). To further confirm that TRPV4 regulated EMT through ZEB1, we transfected ZEB1 siRNA in TRPV4-overexprssing HT-29 cells. As shown in Fig. 3B,
A

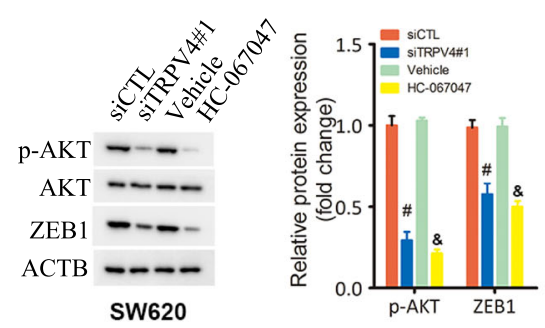

C

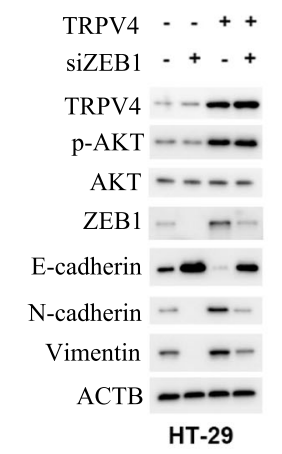

E

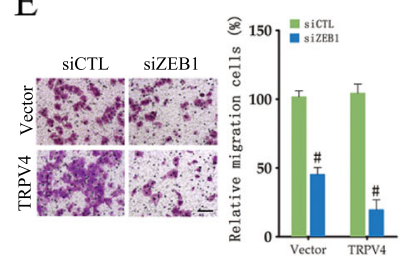

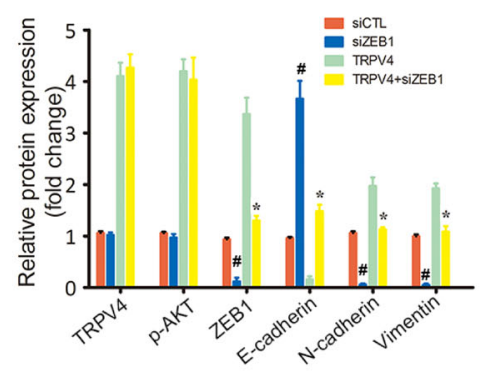

F

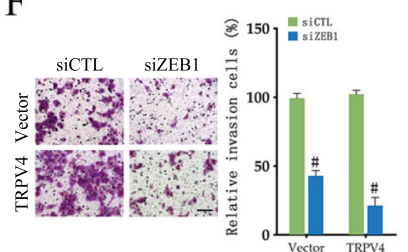

B

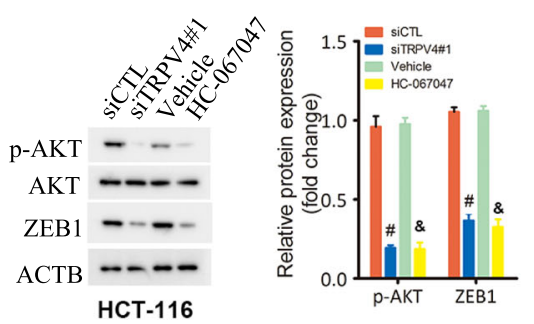

$\mathrm{D}$

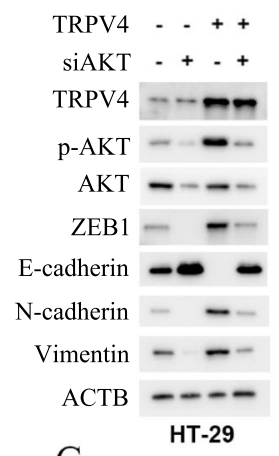

$\mathrm{G}$

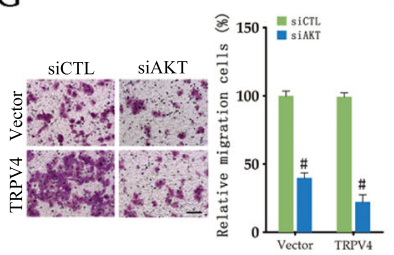

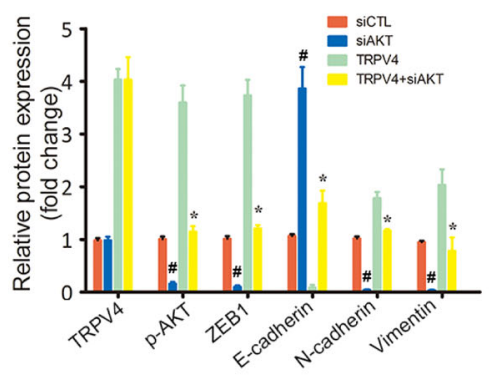

$\mathrm{H}$

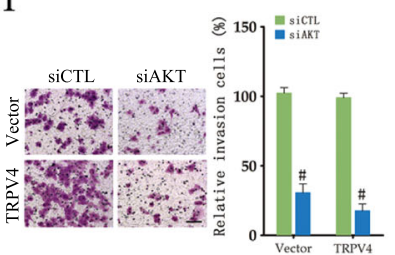

Fig. 3 TRPV4 increases ZEB1 expression to enhance epithelial-mesenchymal transition. A and B Western blot analysis for p-AKT, AKT, ZEB1 and ATCB in HCT-116 and SW620 cells transfected with siCTL and siTRPV4\#1 or treated with Vehicle or HC-067047. C and D representative images and summary data of Western blot demonstrating the effects of ZEB1 siRNA or AKT siRNA on the EMT process induced by TRPV4 overexpression in HT-29 cells. $\mathbf{E}$ and $\mathbf{F}$ representative images and summary data from migration and invasion assay demonstrating the effects of ZEB1 siRNA on TRPV4 overexpression induced cell motility, scale bar: $50 \mu \mathrm{m}$. $\mathbf{G}$ and $\mathbf{H}$ representative images and summary data from migration and invasion assay demonstrating the effects of AKT siRNA on TRPV4 overexpression induced cell motility, scale bar: $50 \mu m$. Values represent the mean \pm SEM, $\#, p<0.05$ compared to siCTL, \&, $p<0.05$ compared to Vehicle, ${ }^{*}, p<0.05$ compared to TRPV4 
knockdown of ZEB1 increased the expression of Ecadherin and decreased levels of $\mathrm{N}$-cadherin and Vimentin expression in TRPV4-overexprssion HT-29 cells. In addition, migration assay and invasion assay showed that ZEB1 silencing reversed TRPV4-overexprssion induced HT-29 cell invasiveness (Fig. $3 \mathrm{C}$ and D). To investigate the possible role of AKT in controlling TRPV4-regulated ZEB1 expression, TRPV4-overexprssing HT-29 cells were treated with AKT siRNA. Notably, knockdown of AKT reduced p-AKT levels, suppressed the expression of ZEB1, N-cadherin, and Vimentin, and increased the expression of E-cadherin in TRPV4-overexprssing HT29 cells (Fig. 3E). Moreover, treatment with siRNA that targeted AKT also attenuated the increase in migration and invasion in TRPV4-overexprssing HT-29 cells (Fig. $3 \mathrm{~F}$ and $\mathrm{G})$. Taken together, these data suggested that TRPV4 indicated the EMT process through upregulating ZEB1 expression, which may be dependent on AKT signaling in CRC cells.

\section{TRPV4 expression is correlated with tumor metastasis in human colon cancer specimens}

To determine the clinical relevance between TRPV4 and tumor metastasis in CRC, we investigated 106 CRC specimens with or without local metastasis to lymphnodes (Table 1). Immunohistochemical (IHC) staining showed that TRPV4 protein expression was mainly observed in the cytoplasm, and ZEB1 protein expression was mainly observed in the nucleus (Fig. 4A). As shown in Fig. 4A and B, the expression of TRPV4 and ZEB1 was elevated in CRC specimens with local metastasis (N1-2) compared to CRC specimens without local metastasis (N0). Furthermore, the expression of TRPV4 was significantly and positively correlated with ZEB1 expression, which suggested the mechanistic relevance and potential regulatory relationship between TRPV4 and ZEB1 in clinical specimens (Fig. 4C). Together, these results indicated that TRPV4 may play a key role in CRC metastasis.

\section{Discussion}

Despite increasing evidences that has indicated the critical roles of TRPV4 in the progression of various cancers, the potential involvement of TRPV4 in CRC metastasis is still not clear. Therefore, in the current study, we aimed to explore the underlying mechanism of TRPV4 controlling metastasis in colon cancer. Here, we showed that the inhibition of TRPV4 suppresseed invasiveness and overexpression of TRPV4-enhanced cell migration and invasion. Furthermore, we demonstrated that AKT-ZEB1 signaling-regulated EMT may be contributed to TRPV4-induced invasiveness (Fig. 4D). More importantly, we observed overexpression of TRPV4 and
Table 1 Demographic information of CRC specimens used for the $\mathrm{IHC}$ analysis

\begin{tabular}{|c|c|c|}
\hline \multirow[b]{2}{*}{ Characteristic } & \multicolumn{2}{|c|}{$\begin{array}{l}\text { All Patients } \\
(n=106)\end{array}$} \\
\hline & $\mathrm{n}$ & $\%$ \\
\hline \multicolumn{3}{|l|}{ Age (years) } \\
\hline$\leq 60$ & 59 & 55.7 \\
\hline$>60$ & 47 & 44.3 \\
\hline \multicolumn{3}{|l|}{ Sex } \\
\hline Male & 42 & 39.6 \\
\hline Female & 64 & 60.4 \\
\hline \multicolumn{3}{|l|}{ Location } \\
\hline Colon & 51 & 48.1 \\
\hline Rectum & 55 & 51.9 \\
\hline \multicolumn{3}{|l|}{ Tumor grade } \\
\hline Well or moderately differentiated & 75 & 70.8 \\
\hline Poorly differentiated & 31 & 29.2 \\
\hline \multicolumn{3}{|l|}{ Pathological T stage } \\
\hline $\mathrm{T} 1$ & 5 & 4.7 \\
\hline $\mathrm{T} 2$ & 24 & 22.6 \\
\hline T3 & 52 & 49.1 \\
\hline T4 & 25 & 23.6 \\
\hline \multicolumn{3}{|l|}{ Pathological N stage } \\
\hline NO & 59 & 55.7 \\
\hline $\mathrm{N} 1$ & 20 & 18.9 \\
\hline N2 & 27 & 25.4 \\
\hline \multicolumn{3}{|l|}{ Pathological M stage } \\
\hline Mo & 106 & 100 \\
\hline
\end{tabular}

ZEB1 in patients with local metastasis, as well as a positive correlation between TRPV4 and ZEB1 expression.

Cumulative evidence has implicated that abnormal expression of the TRPV4 channel contributed to human cancer progression. Xie and colleagues suggested that TRPV4 served as preventive or therapeutic strategies for human gastric cancer [23]. Yu and colleagues reported that inhibition of TRPV4 reduced malignant biological behavior of hepatocellular carcinoma [24]. More recently, in a study carried out by our team, we demonstrated that TRPV4 was overexpressed in CRC and correlated with poor prognosis [13]. Moreover, endogenous TRPV4 expression was higher in HCT-116 and SW620 cells and lower in HT-29 cells [13]. Consistent with the oncogenic properties of TRPV4, in this study we found that genetic knockdown or pharmacological inhibition of TRPV4 suppressed CRC cell migration and invasion. In addition, overexpression of TRPV4 promoted the migration and invasion capabilities of CRC cells. In line with our results, $\mathrm{WH}$ and colleagues suggested that TRPV4 dysfunction decreased aggression in breast 


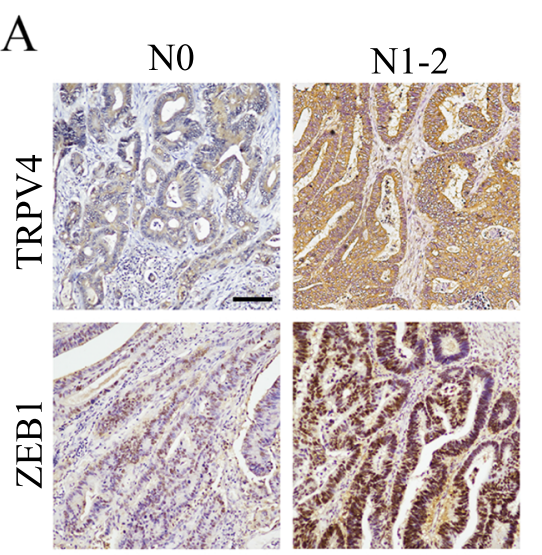

$\mathrm{C}$

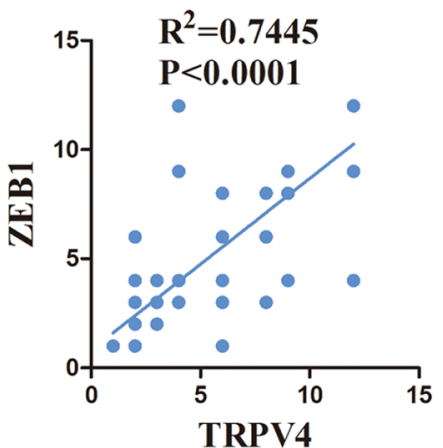

$\mathrm{B}$
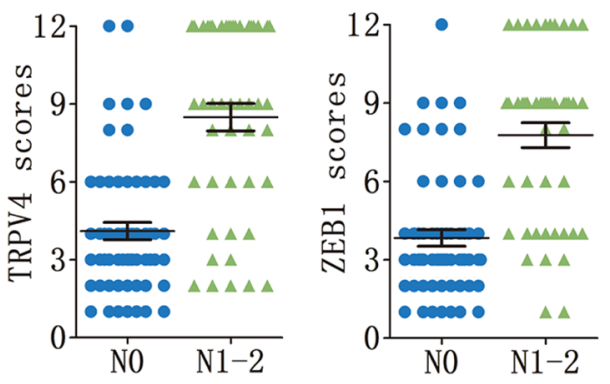

$\mathrm{D}$

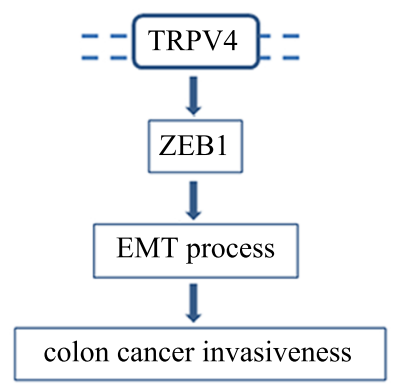

Fig. 4 TRPV4 expression is correlated with tumor metastasis in human colon cancer specimens. $\mathbf{A}$ and $\mathbf{B}$ representative images and summary data of immunohistochemical staining of TRPV4 and ZEB1 in patients with or without lymph node metastasis (NO $n=59$, N1-2 $n=47$ ) Scale bar: $50 \mu \mathrm{m}$. C Pearson correction of TRPV4 expression with ZEB1 $(n=106)$, data were analyzed using the Pearson correlation test. D Signaling connections involved in the TRPV4-modulated epithelial-mesenchymal transition (EMT) process in human colon cancer

cancer cells [12, 25]. Furthermore, Ou Yang-and colleagues proposed that TRPV4 accelerated glioma migration and invasion and served as a potential target for glioma therapy [26]. Therefore, we hypothesized that TRPV4 might be critical for CRC invasiveness, and that inhibition of TRPV4 could induce anti-metastasis in CRC.

Emerging evidence has suggested an important role of EMT in the metastatic process, which resulted in acquiring mesenchymal cell markers and losing epithelial markers [14-16]. Most solid cancers are of epithelial origin, and EMT has been considered an inducer for epithelial cells to acquire the capabilities of motility [1416]. In a previous study, it was shown that E-cadherin regulated cell adhesion, and that low E-cadherin expression facilitated cells to detach from original sites [27]. On the contrary, N-cadherin and Vimentin are positively associated with increased cancer invasiveness [28, 29]. In the present study, inhibition of TRPV4 activity or expression enhanced the expression of E-cadherin and reduced the expression of $\mathrm{N}$-cadherin and Vimentin. Notably, in support of the theory that TRPV4 positively regulated the EMT process, our results showed that overexpression of TRPV4 decreased the expression of Ecadherin and increased the expression of $\mathrm{N}$-cadherin and Vimentin. It is well known that ZEB1 is a key activator of the EMT process in cancer cells [30]. Wang and colleagues suggested that ZEB1 promoted tumor metastasis through the EMT process in liver and breast cancer $[22,31]$. In CRC, Su and colleagues proposed that ZEB1 might enhance EMT and metastasis. In line with this notion, we demonstrated that inhibition of TRPV4 decreased ZEB1 expression. Furthermore, ZEB1 knockdown may reverse the TRPV4-overexpression-induced EMT process and invasiveness. It was previously observed that AKT activation was involved in ZEB1 upregulation [32]. In this study, we found that AKT may play a key role in controlling TRPV4 regulated ZEB1 expression. More importantly, high expression of TRPV4 and ZEB1 was observed in CRC patients with local metastasis. We also indicated that in CRC patients, TRPV4 expression positively correlated with ZEB1 expression. Based on the important role of ZEB1 in EMT, we conclude that there might be a complex network involving TRPV4, ZEB1, EMT and invasiveness in CRC. 
Therefore, our findings strongly supported that the TRPV4/ZEB1 axis, as a key signaling that modulates EMT, may receive special attentive in future studies.

\section{Conclusions}

Taken together, the results obtained in the present study showed that inhibition of TRPV4 suppressed CRC cell migration and invasion. We further uncovered that the invasiveness-inhibitory effect of TRPV4 inhibition was regulated by AKT-ZEB1 signaling through suppression of the EMT process. In this study, we highlighted the role of the TRPV4/ZEB1 axis in indicating EMT, which might hold potential for future diagnostic and therapeutic exploitation.

\section{Supplementary Information}

The online version contains supplementary material available at https://doi. org/10.1186/s12885-021-08970-7.

\section{Additional file 1.}

\section{Acknowledgements}

Not applicable.

\section{Authors' contributions}

Interpretation of analysis of data: P Zhang, J Xu and H Zhang; Preparation of the manuscript: P Zhang and XY Liu; Supervision: P Zhang and XY Liu. The author(s) read and approved the final manuscript.

\section{Funding}

The present study was supported by the National Natural Science Foundation of China (82003108); Natural Science Foundation of Jiangsu Province (BK20190595); The Fundamental Research Funds for the Central Universities (JUSRP11956); Guangdong Basic and Applied Basic Research Foundation (2021A1515010970); Shenzhen Key Medical Discipline Construction Fund (No. SZXK039).

\section{Availability of data and materials}

All data generated or analyzed during this study are included in this published article.

\section{Declarations}

\section{Ethics approval and consent to participate}

The Review Board of the Affiliated Hospital of Jiangnan University approved the clinical samples for research purposes (NO.LS2018020). This study was confirmed to the principles contained in the World Medical Association Declaration of Helsinki. Informed consent was requested as anonymous specimens and was given by all human participants in this study.

\section{Consent for publication}

Not applicable.

\section{Competing interests}

The authors declare that they have no competing interests.

\section{Author details}

${ }^{1}$ Longgang E.N.T. Hospital \& Shenzhen Key Laboratory of E.N.T., Institute of E.N.T, No. 3004 Longgang Avenue, Shenzhen, Guangdong, China. ${ }^{2}$ School of Medicine, Jiangnan University, Wuxi, Jiangsu, China. ${ }^{3}$ School of Medicine, Southern University of Science and Technology, 1088 Xueyuan Avenue, Shenzhen, Guangdong, China.
Received: 22 June 2021 Accepted: 1 November 2021

Published online: 23 November 2021

\section{References}

1. Miller KD, Nogueira L, Mariotto AB, Rowland JH, Yabroff KR, Alfano CM, et al. Cancer treatment and survivorship statistics. CA Cancer J Clin. 2019;69(5): 363-85. https://doi.org/10.3322/caac.21565.

2. Miller KD, Siegel RL, Lin CC, Mariotto AB, Kramer JL, Rowland JH, et al. Cancer treatment and survivorship statistics. CA Cancer J Clin. 2016;66(4): 271-89. https://doi.org/10.3322/caac.21349.

3. van Kalsbeek RJ, van der Pal HJH, Hjorth L, Winther JF, Michel G, Haupt R, et al. The European multistakeholder PanCareFollowUp project: novel, person-centred survivorship care to improve care quality, effectiveness, costeffectiveness and accessibility for cancer survivors and caregivers. Eur J Cancer. 2021;153:74-85. https://doi.org/10.1016/j.ejca.2021.05.030.

4. Gallicchio L, Tonorezos E, de Moor JS, Elena J, Farrell M, Green P, et al. Evidence Gaps in Cancer Survivorship Care: A Report from the 2019 National Cancer Institute Cancer Survivorship Workshop. J Natl Cancer Inst. 2021;113(9):1136-42.

5. Miller KD, Fidler-Benaoudia M, Keegan TH, Hipp HS, Jemal A, Siegel RL. Cancer statistics for adolescents and young adults, 2020. CA Cancer J Clin. 2020;70(6):443-59. https://doi.org/10.3322/caac.21637.

6. Mohile SG, Hurria A, Cohen HJ, Rowland JH, Leach CR, Arora NK, et al. Improving the quality of survivorship for older adults with cancer. Cancer. 2016;122(16):2459-568. https://doi.org/10.1002/cncr.30053.

7. Hanahan D, Weinberg RA. Hallmarks of cancer: the next generation. Cell. 2011;144(5):646-74. https://doi.org/10.1016/j.cell.2011.02.013.

8. Tørring ML, Murchie P, Hamilton W, Vedsted P, Esteva M, Winget M, et al. Evidence of advanced stage colorectal cancer with longer diagnostic intervals: a pooled analysis of seven primary care cohorts comprising 11720 patients in five countries. Br J Cancer. 2017;177(6):888-97. https://doi.org/1 $0.1038 /$ bjc.2017.236

9. Chaffer $\mathrm{CL}$, Weinberg RA. A perspective on cancer cell metastasis. Science. 2011;331(6024):1559-64. https://doi.org/10.1126/science.1203543.

10. Nilius B, Voets T. The puzzle of TRPV4 channelopathies. EMBO Rep. 2013; 14(2):152-63. https://doi.org/10.1038/embor.2012.219.

11. Zhang P, Sun C, Li H, Tang C, Kan H, Yang Z, et al. TRPV4 (transient receptor potential Vanilloid 4) mediates endothelium-dependent contractions in the aortas of hypertensive mice. Hypertension. 2018;71(1):134-42. https://doi. org/10.1161/HYPERTENSIONAHA.117.09767.

12. Lee $W H$, Choong LY, Jin TH, Mon NN, Chong S, Liew CS, et al. TRPV4 plays a role in breast cancer cell migration via Ca2+-dependent activation of AKT and downregulation of E-cadherin cell cortex protein. Oncogenesis. 2017; 6(5):e338. https://doi.org/10.1038/oncsis.2017.39.

13. Liu X, Zhang P, Xie C, Sham KWY, Ng SSM, Chen Y, et al. Activation of PTEN by inhibition of TRPV4 suppresses colon cancer development. Cell Death Dis. 2019;10(6):460. https://doi.org/10.1038/s41419-019-1700-4.

14. Boesch M, Spizzo G, Seeber A. Concise review: aggressive colorectal cancer: role of epithelial cell adhesion molecule in cancer stem cells and epithelialto-mesenchymal transition. Stem Cells Transl Med. 2018;7(6):495-501. https://doi.org/10.1002/sctm.17-0289.

15. Loboda A, Nebozhyn MV, Watters JW, Buser CA, Shaw PM, Huang PS, et al. EMT is the dominant program in human colon cancer. BMC Med Genet. 2011:4(1):9. https://doi.org/10.1186/1755-8794-4-9.

16. Craene BD, Berx G. Regulatory networks defining EMT during cancer initiation and progression. Nat Rev Cancer. 2013;13(2):97-110. https://doi. org/10.1038/nrc3447.

17. Zhang P, Liu X, Li H, Chen Z, Yao X, Jin J, et al. TRPC5-induced autophagy promotes drug resistance in breast carcinoma via CaMKKß/ AMPKa/mTOR pathway. Sci Rep. 2017;7(1):3158. https://doi.org/10.1038/ s41598-017-03230-w.

18. Liu X, Han X, Wan X, He C, Wang Y, Mao A, et al. SPZ1 is critical for chemoresistance and aggressiveness in drug-resistant breast cancer cells. Biochem Pharmacol. 2018;156:43-51. https://doi.org/10.1016/j.bcp.2 018.07.046.

19. Liu X, Wang T, Wang Y, Chen Z, Hua D, Yao X, et al. Orai 1 is critical for Notch-driven aggressiveness under hypoxic conditions in triple-negative breast cancers. Biochim Biophys Acta Mol Basis Dis. 2018;1864(4 Pt A):975-86.

20. Lamprecht S, Kaller M, Schmidt EM, Blaj C, Schiergens TS, Engel J, et al. PBX3 is part of an EMT regulatory network and indicates poor outcome in 
colorectal Cancer. Clin Cancer Res. 2018;24(8):1974-86. https://doi.org/10.11 58/1078-0432.CCR-17-2572.

21. Lee SY, Jeong EK, Ju MK, Jeon HM, Kim MY, Kim CH, et al. Induction of metastasis, cancer stem cell phenotype, and oncogenic metabolism in cancer cells by ionizing radiation. Mol Cancer. 2017;16(1):10. https://doi. org/10.1186/s12943-016-0577-4.

22. Wang Y, Bu F, Royer C, Serres S, Larkin JR, Soto MS, et al. ASPP2 controls epithelial plasticity and inhibits metastasis through beta-catenin-dependent regulation of ZEB1. Nat Cell Biol. 2014;16(11):1092-104. https://doi.org/10.1 038/ncb3050.

23. Xie R, Xu J, Xiao Y, Wu J, Wan H, Tang B, et al. Calcium promotes human gastric cancer via a novel coupling of calcium-sensing receptor and TRPV4 channel. Cancer Res. 2017;77(23):6499-512. https://doi.org/10.1158/0008-54 72.CAN-17-0360.

24. Fang Y, Liu G, Xie C, Qian K, Lei X, Liu Q, et al. Pharmacological inhibition of TRPV4 channel suppresses malignant biological behavior of hepatocellular carcinoma via modulation of ERK signaling pathway. Biomed Pharmacother. 2018;101:910-9. https://doi.org/10.1016/j.biopha.2018.03.014.

25. Lee WH, Choong LY, Mon NN, Lu S, Lin Q, Pang B, et al. TRPV4 regulates breast cancer cell extravasation, stiffness and actin cortex. Sci Rep. 2016;6(1): 27903. https://doi.org/10.1038/srep27903.

26. Ou-Yang Q, Li B, Xu M. Liang H.TRPV4 promotes the migration and invasion of glioma cells via AKT/Rac1 signaling. Biochem Biophys Res Commun. 2018:503(2):876-81. https://doi.org/10.1016/j.bbrc.2018.06.090.

27. Tsanou E, Peschos D, Batistatou A, Charalabopoulos A, Charalabopoulos K. The E-cadherin adhesion molecule and colorectal cancer. A global literature approach. Anticancer Res. 2008;28(6A):3815-26.

28. Nakajima S, Doi R, Toyoda E, Tsuji S, Wada M, Koizumi M, et al. N-cadherin expression and epithelial-mesenchymal transition in pancreatic carcinoma. Clin Cancer Res. 2004;10(12 Pt 1):4125-33. https://doi.org/10.1158/10780432.CCR-0578-03.

29. Chaw SY, Majeed AA, Dalley AJ, Chan A, Stein S, Farah CS. Epithelial to mesenchymal transition (EMT) biomarkers--E-cadherin, beta-catenin, APC and Vimentin--in oral squamous cell carcinogenesis and transformation. Oral Oncol. 2012;48(10):997-1006. https://doi.org/10.1016/j.oraloncology.2 012.05.011.

30. Larsen JE, Nathan V, Osborne JK, Farrow RD, Deb D, Sullivan JP, et al. ZEB1 drives epithelial-to-mesenchymal transition in lung cancer. J Clin Invest. 2016;126(9):3219-35. https://doi.org/10.1172/JCI76725.

31. Wang $Y$, Wen M, Kwon Y, Xu Y, Liu Y, Zhang P, et al. CUL4A induces epithelial-mesenchymal transition and promotes cancer metastasis by regulating ZEB1 expression. Cancer Res. 2014;74(2):520-31. https://doi.org/1 0.1158/0008-5472.CAN-13-2182.

32. Spaderna S, Schmalhofer O, Wahlbuhl M, Dimmler A, Bauer K, Sultan A, et al. The transcriptional repressor ZEB1 promotes metastasis and loss of cell polarity in cancer. Cancer Res. 2008;68(2):537-44. https://doi.org/10.1158/ 0008-5472.CAN-07-5682.

\section{Publisher's Note}

Springer Nature remains neutral with regard to jurisdictional claims in published maps and institutional affiliations.

Ready to submit your research? Choose BMC and benefit from:

- fast, convenient online submission

- thorough peer review by experienced researchers in your field

- rapid publication on acceptance

- support for research data, including large and complex data types

- gold Open Access which fosters wider collaboration and increased citations

- maximum visibility for your research: over $100 \mathrm{M}$ website views per year

At BMC, research is always in progress.

Learn more biomedcentral.com/submissions 